\title{
Estrogen Receptor $\alpha$ Variants Affect Age at Onset of Alzheimer's Disease in a Multiethnic Female Cohort
}

\author{
S.C. Janickia-c N. Park ${ }^{a, b} \quad$ R. Cheng ${ }^{a, b} \quad$ L.N. Clark ${ }^{a, e, f} \quad$ J.H. Lee ${ }^{a, b, f, g}$ \\ N. Schupf $f^{a}, b, d, g$
}

a Taub Institute for Research on Alzheimer's Disease and the Aging Brain, ${ }^{b}$ Gertrude $\mathrm{H}$. Sergievsky Center, Departments of ${ }^{\mathrm{C}}$ Neurology, ${ }^{\mathrm{d}}$ Psychiatry and ${ }^{\mathrm{e}}$ Pathology and Cell Biology, and ${ }^{\mathrm{f} C e n t e r}$ for Human Genetics, College of Physicians and Surgeons, Columbia University, and 9 Departments of Epidemiology and Psychiatry, Columbia University Medical Center, New York, N.Y., USA

\section{Key Words}

Age of onset - Alzheimer's disease - Hispanics - Estrogen receptors - Gene polymorphism · Genetic association studies · Estrogen receptor $\alpha \cdot$ Late-onset Alzheimer's disease

\begin{abstract}
Background/Aims: Few studies of gene variants that affect estrogen activity investigate their association with age at onset of Alzheimer's disease (AD) in women of different ethnicities. We examined the influence of ESR1 polymorphisms on age at onset of AD in a multiethnic cohort of women. Methods: Among 1,436 women participating in the Washington Heights Inwood Columbia Aging Project, association with age at AD onset was assessed for 41 singlenucleotide polymorphisms (SNPs) on the ESR1 gene using Cox proportional hazard models, adjusting for presence of an $A P O E \& 4$ allele, years of education, and body mass index. Results: Six SNPs in self-identified White women were protectively associated with delayed age of AD onset in this self-identified group, including the two restriction fragment length polymorphisms PvuII (rs2234693) and XbaI (rs9340799) (HR range $=0.420-0.483)$. Two separate SNPs were found to affect age of AD onset in self-identified Black women. Conclusions: ESR1 polymorphisms affect age of onset of $A D$ in women, and risk alleles vary by ethnicity. These effects are possibly due to different linkage disequilibrium patterns or differences in comorbid environmental or cultural risk factors mediating the SNP effect on risk for AD.
\end{abstract}




\section{Introduction}

Estrogens are important in maintaining brain function in regions typically affected by Alzheimer's disease (AD), and variations in estrogen exposure over the lifetime may affect cognitive decline associated with $\mathrm{AD}[1,2]$. Numerous papers have established that estrogen may have beneficial effects on multiple pathways that affect risk for AD. Estrogens promote the growth and survival of cholinergic neurons [3, 4], increase cholinergic activity [5], have antioxidant properties [6], and promote the nonamyloidogenic metabolism of the amyloid precursor protein [7]. Estrogens also play an important role in regulation of the vascular endothelium where they activate rapid vasodilatation, exert anti-inflammatory effects, stimulate endothelial growth and migration, and protect the vessels from atherosclerotic degeneration by elevating nitric oxide and prostaglandin levels $[8,9]$. However, evaluating the role of hormones and enzymes in aging and cognition is difficult since many hormone levels decline with age. It is likely that polymorphisms in genes encoding the estrogen pathway contribute to variations in lifetime hormone exposure, including age-related changes in hormone levels. Estrogen exerts its action through at least two receptors, estrogen receptor $\alpha(E R \alpha)$, encoded by ESR1 on chromosome 6q25.1, and estrogen receptor $\beta$ (ER $\beta$ ) [2]. The association of polymorphisms in ESR1 with risk for AD has been investigated in a number of studies, but findings have been inconsistent [10-23]. However, most studies have been conducted in relatively homogeneous ethnic groups, and few polymorphisms have been assessed in a multiethnic cohort. Examination of single-nucleotide polymorphisms (SNPs) in multiracial groups which are evaluated without taking ethnicity into account may have several limitations, including a loss of significant association due to different allele frequencies, different linkage disequilibrium (LD) patterns between ethnicities, or differences in the distribution of comorbid conditions and risk factors for AD by ethnic group. In this study, we examined the relationship between ESR1 SNPs and the risk for AD in a multiethnic self-identified ethnicity as well as by genetic population ancestry markers [24]. The aims of this study were to confirm previous findings of ESR1 polymorphisms which were found to be significantly associated with risk for AD, to identify additional SNPs which confer risk for AD using a denser set of SNPs than in previous studies, and to examine whether ESR1 variants would affect risk for AD differently in groups of women with different self-identified ethnicity. We hypothesized that genetic variants would demonstrate different patterns of association between groups of different ethnicities due to different allele frequencies or LD patterns between ethnic groups, as well as varying environmental risk factors.

\section{Materials and Methods}

\section{Subjects}

The initial cohort included 1,686 women participating in the Washington Heights Inwood Columbia Aging Project (WHICAP), a prospective study of aging and dementia among Medicare recipients aged 65 years and older, residing in northern Manhattan. Each subject underwent an in-person interview of health and functional ability followed by a standardized medical assessment and neuropsychological battery [25]. Assessments were conducted at 18- to 24-month intervals over a mean of 6.1 years of follow-up. The population from which the participants were drawn was comprised of individuals from several different countries of origin representing three broadly self-identified ethnicities (Caribbean Hispanic, $n=400$, AfricanAmerican, $n=485$, and non-Hispanic White of European ancestry, $n=551$ ). The sampling strategies and recruitment of these three cohorts have been described in detail elsewhere [24].

AD diagnosis was based on NINCDS-ADRDA criteria. Participants were classified as nondemented if they remained without cognitive or functional decline through their last study assessment $(n=1,107)$. In addition, participants were classified as having incident AD if they were nondemented at the baseline visit and were then classified as having probable or possible AD by NINCDS-ADRDA criteria at any later study visit $(n=329)$. 
Janicki et al.: Estrogen Receptor $\alpha$ Variants Affect Age at Onset of Alzheimer's Disease in a Multiethnic Female Cohort

Fig. 1. Plot of WHICAP participants by AIM-defined ancestry vs. HapMap populations. For WHICAP participants, yellow: predominantly Caucasian AIMdefined ancestry; green: admixed/Hispanic AIM-defined ancestry; blue: predominantly African AIM-defined ancestry. For HapMap populations, light brown: ancestrally homogenous Caucasian population (CEPH); light blue: ancestrally homogenous Yoruban Black population (YRI); red: ancestrally homogenous East Asian population (CHJA).

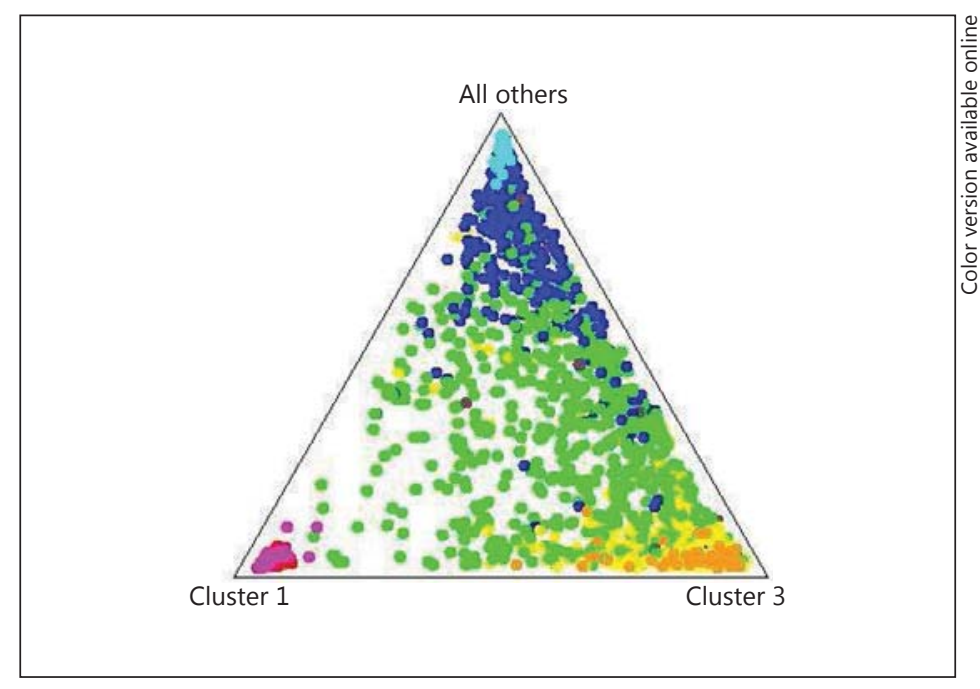

Those with incident AD had no other medical or psychiatric conditions that might mimic AD including other neurologic conditions such as Parkinson's disease or stroke. Age at initial diagnosis of AD was used to estimate age at onset of dementia.

\section{Standard Protocol Approvals, Registrations and Patient Consents}

This study was reviewed and approved by the Columbia University institutional review board, and written informed consent was previously obtained from all subjects.

\section{DNA Isolation, SNP Selection and Genotyping}

Genomic DNA was extracted from total peripheral blood leukocytes using standard methods. We used a multistep selection process to identify candidate SNPs for genotyping. We first selected SNPs within ESR1 that were previously reported to be associated with an increased incidence or earlier age at onset of AD in any population. We then referenced the International HapMap Project (www.hapmap.org) to select tagging SNPs in both Caucasian and African populations. To provide sufficient coverage of the gene, we selected SNPs to maintain a pairwise $\mathrm{r}^{2}$ threshold of 0.8 in SNPs with a minimum minor allele frequency (MAF) of 0.2. We obtained an average intermarker distance of approximately $6.2 \mathrm{~kb}$ pairs between SNPs, which provided good coverage of the gene as viewed on LD maps (online suppl. fig. 1-3; for all online suppl. material, see www. karger.com/doi/10.1159/000355559).

Forty-one ESR1 SNPs as well as 100 ancestry informative markers (AIMs) were genotyped in a total of 1,436 samples using Illumina GoldenGate custom panels and the Illumina IScan platform. Genotyping was performed according to standard protocols (www.Illumina.com). The complete list of ESR1 SNPs that were genotyped, along with their MAF by self-identified ethnicity, is presented in table 1 . Duplicate genotyping was performed on $10 \%$ of samples to verify accuracy, and the concordance rate was greater than $97 \%$.

\section{Assessment of Ethnicity and Genetic Population Ancestry}

Participants were first categorized by self-identified ethnicity as given at time of study enrollment (with self-identified categories including Black of non-Hispanic ancestry, White of non-Hispanic ancestry, and Hispanic), as most previous studies on ESR1 polymorphisms and AD have used this means of classification. Afterwards, participants were recategorized by genetic population ancestry. To control for potential confounding that can be generated by population stratification, we used a set of 100 unlinked AIMs from a panel of 650Y Illumina SNPs to assess population structure. The AIMs were selected because they have allele frequencies that are significantly different among the three ethno-racial groups: non-Hispanic Whites, nonHispanic African, and individuals of Mexican/Central American ancestry. To assess population stratification, we performed population structure analysis as implemented in the STRUCTURE program [26, 27]. To anchor ancestry, we included data from Caucasians (CEPH), Yorubans (YRI) and Mexican/Central Americans from the HapMap project (fig. 1). Our self-identified White population closely aligned with the Caucasian (CEPH) 
Dementia

Cognitive Disorders
Dement Geriatr Cogn Disord 2014;38:200-213

DOI: $10.1159 / 000355559$

Janicki et al.: Estrogen Receptor $\alpha$ Variants Affect Age at Onset of Alzheimer's Disease in a Multiethnic Female Cohort

Table 1. Investigated ESR1 SNPs

\begin{tabular}{|c|c|c|c|c|c|c|c|}
\hline $\begin{array}{l}\text { No. of } \\
\text { SNP }\end{array}$ & SNP & Position & $\begin{array}{l}\text { Distance, } \\
\text { bp }\end{array}$ & $\begin{array}{l}\text { Minor } \\
\text { allele }\end{array}$ & $\begin{array}{l}\text { MAF of self- } \\
\text { identified White }\end{array}$ & $\begin{array}{l}\text { MAF of self- } \\
\text { identified Hispanic }\end{array}$ & $\begin{array}{l}\text { MAF of self- } \\
\text { identified Black }\end{array}$ \\
\hline 1 & rs2077647 & 152171020 & & C & 0.5 & 0.5 & 0.5 \\
\hline 2 & rs17847065 & 152171427 & 407 & A & 0.0 & 0.0 & 0.0 \\
\hline 3 & rs11155814 & 152193127 & 21,700 & G & 0.1 & 0.3 & 0.5 \\
\hline 4 & rs7761133 & 152193806 & 679 & G & 0.2 & 0.4 & 0.6 \\
\hline 5 & rs17081749 & 152193868 & 62 & $\mathrm{C}$ & 0.1 & 0.3 & 0.4 \\
\hline 6 & rs6903763 & 152195099 & 679 & A & 0.1 & 0.1 & 0.2 \\
\hline 7 & rs6909023 & 152195640 & 00.541 & $\mathbf{A}$ & 0.1 & 0.1 & 0.2 \\
\hline 8 & rs6937568 & 152195907 & 267 & $\mathrm{G}$ & 0.0 & 0.1 & 0.2 \\
\hline 9 & rs827421 & 152199065 & 3,158 & A & 0.5 & 0.5 & 0.4 \\
\hline 10 & rs17081777 & 152199272 & 207 & $\mathrm{G}$ & 0.0 & 0.1 & 0.1 \\
\hline 11 & rs6902771 & 152199824 & 00.552 & $\mathbf{A}$ & 0.5 & 0.5 & 0.5 \\
\hline 12 & rs3853250 & 152201843 & 02,019 & C & 0.5 & 0.5 & 0.5 \\
\hline 13 & rs4870056 & 152204170 & 02,327 & $\mathbf{A}$ & 0.5 & 0.5 & 0.5 \\
\hline 14 & rs2234693 & 152205278 & 01,108 & $\mathrm{C}$ & 0.5 & 0.5 & 0.5 \\
\hline 15 & rs9340799 & 152205324 & 000.46 & G & 0.4 & 0.3 & 0.3 \\
\hline 16 & rs9322332 & 152208744 & 03,420 & $\mathbf{A}$ & 0.5 & 0.4 & 0.4 \\
\hline 17 & rs3936674 & 152209254 & 510 & A & 0.3 & 0.2 & 0.1 \\
\hline 18 & rs712221 & 152222184 & 12,930 & $\mathrm{~T}$ & 0.5 & 0.5 & 0.4 \\
\hline 19 & rs1709183 & 152235939 & 13,755 & $\mathrm{G}$ & 0.2 & 0.3 & 0.4 \\
\hline 20 & rs11155819 & 152241302 & 5,363 & $\mathrm{G}$ & 0.3 & 0.3 & 0.1 \\
\hline 21 & rs9340835 & 152241874 & 572 & A & 0.3 & 0.3 & 0.3 \\
\hline 22 & rs9322335 & 152242072 & 198 & A & 0.2 & 0.3 & 0.3 \\
\hline 23 & rs9322338 & 152242692 & 620 & A & 0.1 & 0.2 & 0.5 \\
\hline 24 & rs6557170 & 152245047 & 2,355 & A & 0.2 & 0.2 & 0.1 \\
\hline 25 & rs9478251 & 152245222 & 175 & $\mathrm{C}$ & 0.0 & 0.2 & 0.3 \\
\hline 26 & rs2347923 & 152269364 & 24,142 & $\mathrm{C}$ & 0.3 & 0.4 & 0.4 \\
\hline 27 & rs2347867 & 152271793 & 2,429 & $\mathrm{G}$ & 0.3 & 0.5 & 0.6 \\
\hline 28 & rs6557171 & 152276536 & 4,743 & A & 0.3 & 0.4 & 0.4 \\
\hline 29 & rs4870062 & 152279561 & 3,025 & $\mathrm{C}$ & 0.3 & 0.4 & 0.5 \\
\hline 30 & rs4583998 & 152302611 & 23,050 & $\mathrm{~A}$ & 0.3 & 0.5 & 0.5 \\
\hline 31 & rs9371564 & 152304056 & 1,445 & A & 0.3 & 0.5 & 0.6 \\
\hline 32 & rs3020377 & 152314341 & 10,285 & A & 0.6 & 0.5 & 0.3 \\
\hline 33 & rs1884051 & 152325222 & 10,881 & $\mathrm{G}$ & 0.4 & 0.4 & 0.5 \\
\hline 34 & rs985695 & 152328648 & 3,426 & A & 0.2 & 0.3 & 0.4 \\
\hline 35 & rs726281 & 152344521 & 15,873 & $\mathrm{G}$ & 0.2 & 0.5 & 0.7 \\
\hline 36 & rs2982684 & 152348147 & 03,626 & $\mathbf{A}$ & 0.1 & 0.1 & 0.2 \\
\hline 37 & rs12212176 & 152351950 & 3,803 & A & 0.2 & 0.1 & 0.1 \\
\hline 38 & rs7757956 & 152359083 & 7,133 & $\mathrm{~A}$ & 0.1 & 0.2 & 0.2 \\
\hline 39 & rs9340954 & 152362115 & 3,032 & $\mathrm{C}$ & 0.3 & 0.4 & 0.6 \\
\hline 40 & rs722208 & 152364828 & 2,713 & G & 0.3 & 0.4 & 0.6 \\
\hline 41 & rs2207396 & 152424325 & 59,497 & A & 0.2 & 0.2 & 0.2 \\
\hline
\end{tabular}

Bold indicates significance in any self-identified ethnicity or AIM-defined genetic ancestry.

samples in the HapMap dataset, and our self-identified Black population clustered around the Yoruban (YRI) samples. As expected, Caribbean Hispanics clearly showed admixture of Caucasian (CEPH) and Yoruban (YRI) genetic population ancestry, and the range of admixture varied widely. We then classified participants into groups of predominant Caucasian ancestry as defined by the AIMs index (defined as $\geq 0.6$ AIMs consistent with CEPH profile, $n=551$ ) versus those of predominant African ancestry (defined as $\geq 0.6$ AIMs consistent with YRI profile, $n=485$ ). In doing so, individuals previously self-identified as Hispanic were reclassified as being of predominantly Caucasian or predominantly African AIM-defined ancestry (if their AIMs index scores were $\geq 0.6 \mathrm{CEPH}$ or YRI, respectively), or admixed/Hispanic if they did not have one predominant genetic ancestry $(n=400)$. 
Dementia

Cognitive Disorders

Table 2. Population characteristics

\begin{tabular}{l|l}
\hline Dement Geriatr Cogn Disord 2014;38:200-213 \\
\hline DOI: $\underline{10.1159 / 000355559}$ & $\begin{array}{l}\text { @ 2014 S. Karger AG, Basel } \\
\text { www.karger.com/dem }\end{array}$ \\
\hline
\end{tabular}

Janicki et al.: Estrogen Receptor $\alpha$ Variants Affect Age at Onset of Alzheimer's Disease in a Multiethnic Female Cohort

\begin{tabular}{lcc}
\hline Characteristics & Nondemented & $\begin{array}{l}\text { Incident } \\
\text { AD }\end{array}$ \\
\hline Sample size & 1,107 & 329 \\
Age at time of enrollment* & $75.1 \pm 5.8$ & $77.4 \pm 6.3$ \\
BMI & $28.1 \pm 5.7$ & $27.8 \pm 5.8$ \\
Years of education* & $10.5 \pm 4.6$ & $7.5 \pm 4.7$ \\
Diagnosis of diabetes mellitus & $174(15.9)$ & $60(18.2)$ \\
Current smokers & $96(8.6)$ & $31(9.4)$ \\
At least 1 copy APOE $\varepsilon 4$ & $285(26.0)$ & $91(28.9)$ \\
Self-identified ethnicity* & $340(89.5)$ & $40(10.5)$ \\
$\quad$ White & $392(68.4)$ & $181(31.6)$ \\
$\quad$ Hispanic & $375(77.6)$ & $108(22.4)$ \\
\hline
\end{tabular}

Values are means \pm SD or $n(\%){ }^{*} \mathrm{p} \leq 0.05$

Potential Confounders

Potential confounders included the following: years of education, which was found to be independently associated with risk for AD in our group (table 2); the presence of at least 1 APOE $\varepsilon 4$ allele, which was included as a potential confounder because of its strong association with risk for AD in previous studies and because the allele frequencies of the $\varepsilon 4$ allele vary substantially by race and ethnicity [28], and body mass index (BMI), included because of the association of adipose tissue with higher estrogen levels [29-31]. Participants were classified according to the presence or absence of at least 1 APOE $\varepsilon 4$ allele. Height and weight were measured at the initial evaluation to compute BMI. Other potential vascular risk factor confounders, including smoking and history of diabetes mellitus, were not included in the analyses because they were not found to be associated with risk for AD in our group (table 2).

\section{Statistical Analyses}

Prior to association analysis, we assessed whether each SNP was in Hardy-Weinberg equilibrium. This analysis was performed separately within each self-identified ethnicity as well as within each AIM-defined group of unaffected individuals using the $\chi^{2}$ goodness-of-fit test in Haploview [32]. We used Cox proportional hazards modeling to assess the relationship between ESR1 genotypes and age at onset of AD, adjusting for presence of at least 1 APOE $\varepsilon 4$ allele, years of education and BMI. To minimize the risk for a false-positive finding from rare variants and multiple testings, we computed empirical $\mathrm{p}$ values by generating the null distribution on the basis of 1,000 replicates of analyses. The use of empirical $p$ values corrects for the fact that multiple analyses were done. Cox modeling was done by stratifying first by self-reported ethnicity and then by AIM-defined ancestry. We hypothesized that differences in associations between these two sets of analyses might reflect culturally associated environmental risk factors for AD within groups defined by selfreport. Conversely, similarities in significant SNPs between the two analyses would suggest a more direct genetic effect of ESR1 polymorphisms on risk for AD. The time-to-event variable was age at onset for participants who developed $\mathrm{AD}$ and age at last assessment for participants who remained nondemented throughout the follow-up period.

To provide the most robust model for observing an effect of the minor allele, SNPs were analyzed using a dominant model, in which participants homozygous for the common allele were used as the reference group. The risk group included participants who were heterozygous or homozygous for the minor allele.

\section{Results}

Demographic Characteristics

Table 2 presents the demographic characteristics of our cohort. The mean age of the participants at baseline was $77.0 \pm 6.7$ years (range $=65-95$ ). Mean length of follow-up was $6.1 \pm 4.3$ years. The majority of women were self-identified as Hispanic $(n=573,39.9 \%)$ and 
Dementia

Cognitive Disorders

Table 3. Characteristics by selfidentified ethnicity

\begin{tabular}{l|l}
\hline Dement Geriatr Cogn Disord 2014;38:200-213 \\
\hline DOI: $\underline{10.1159 / 000355559}$ & $\begin{array}{l}\text { (c) 2014 S. Karger AG, Basel } \\
\text { www.karger.com/dem }\end{array}$ \\
\hline
\end{tabular}

Janicki et al.: Estrogen Receptor $\alpha$ Variants Affect Age at Onset of Alzheimer's Disease in a Multiethnic Female Cohort

\begin{tabular}{llll}
\hline Characteristics & $\begin{array}{l}\text { Self- } \\
\text { identified } \\
\text { White }\end{array}$ & $\begin{array}{l}\text { Self- } \\
\text { identified } \\
\text { Hispanic }\end{array}$ & $\begin{array}{l}\text { Self- } \\
\text { identified } \\
\text { Black }\end{array}$ \\
\hline Sample size, $\mathrm{n}$ & 380 & 573 & 483 \\
Age at time of enrollment* & $77.9 \pm 7.2$ & $75.3 \pm 6.9$ & $77.3 \pm 6.8$ \\
BMI* & $26.2 \pm 5.1$ & $28.2 \pm 6.3$ & $28.3 \pm 5.1$ \\
Years of education* & $12.4 \pm 3.8$ & $6.0 \pm 4.3$ & $11.0 \pm 3.8$ \\
At least 1 copy APOE $\varepsilon 4^{*}$ & $83(21.8)$ & $137(23.9)$ & $186(32.3)$ \\
\hline
\end{tabular}

Values are means \pm SD or $n(\%) .{ }^{*} \mathrm{p} \leq 0.05$

Table 4. ESR1 SNPs associated with incident AD, by self-identified ethnicity

\begin{tabular}{|c|c|c|c|c|c|c|c|c|c|c|c|c|c|c|c|}
\hline \multirow{2}{*}{$\begin{array}{l}\text { No. } \\
\text { of } \\
\text { SNP }\end{array}$} & \multicolumn{5}{|c|}{ Self-identified White } & \multicolumn{5}{|c|}{ Self-identified Hispanic } & \multicolumn{5}{|c|}{ Self-identified Black } \\
\hline & SNP & $\mathrm{n}$ & $\mathrm{AD}$ & $\operatorname{HR}(95 \% \mathrm{CI})$ & $\begin{array}{l}\text { emp. } \\
\text { p value }\end{array}$ & SNP & $\mathrm{n}$ & $\mathrm{AD}$ & $\operatorname{HR}(95 \% \mathrm{CI})$ & $\begin{array}{l}\text { emp. } \\
\text { p value }\end{array}$ & SNP & $\mathrm{n}$ & $\mathrm{AD}$ & $\operatorname{HR}(95 \% \mathrm{CI})$ & $\begin{array}{l}\text { emp. } \\
\text { p value }\end{array}$ \\
\hline \multirow[t]{3}{*}{1} & \multicolumn{5}{|c|}{ rs2077647 (152171020); MAF (C): 0.5} & \multicolumn{5}{|c|}{ rs2077647 (152171020); MAF (C): 0.5} & \multicolumn{5}{|c|}{ rs2077647 (152171020); MAF (C): 0.5} \\
\hline & $\mathrm{CC} / \mathrm{CT}$ & 279 & 33 & $1.761(0.680-4.556)$ & 0.244 & $\mathrm{CC} / \mathrm{CT}$ & 146 & 282 & $1.183(0.834-1.680)$ & 0.346 & $\mathrm{CC} / \mathrm{CT}$ & 358 & 286 & $0.629(0.414-0.955)$ & 0.030 \\
\hline & TT & 97 & 6 & ref. & & TT & 418 & 103 & ref. & & $\mathrm{TT}$ & 124 & 88 & ref. & \\
\hline \multirow[t]{3}{*}{11} & \multicolumn{5}{|c|}{ rs6902771 (152199824); MAF (A): 0.5} & \multicolumn{5}{|c|}{ rs6902771 (152199824); MAF (A): 0.5} & \multicolumn{5}{|c|}{ rs6902771 (152199824); MAF (A): 0.5} \\
\hline & AA/AG & 272 & 21 & $0.437(0.224-0.852)$ & 0.015 & $\mathrm{AA} / \mathrm{AG}$ & 399 & 128 & $1.072(0.763-1.505)$ & 0.690 & $\mathrm{AA} / \mathrm{AG}$ & 352 & 85 & $1.361(0.831-2.227)$ & 0.220 \\
\hline & GG & 94 & 17 & ref. & & GG & 158 & 47 & ref. & & GG & 114 & 22 & ref. & \\
\hline \multirow[t]{3}{*}{12} & \multicolumn{5}{|c|}{ rs3853250 (152201843); MAF (C): 0.5} & \multicolumn{5}{|c|}{ rs3853250 (152201843); MAF (C): 0.5} & \multicolumn{5}{|c|}{ rs3853250 (152201843); MAF (C): 0} \\
\hline & $\mathrm{CC} / \mathrm{AC}$ & 267 & 21 & $0.442(0.226-0.862)$ & 0.017 & $\mathrm{CC} / \mathrm{AC}$ & 411 & 131 & $1.076(0.762-1.518)$ & 0.678 & $\mathrm{CC} / \mathrm{AC}$ & 368 & 87 & $1.276(0.762-2.137)$ & 0.354 \\
\hline & AA & 99 & 17 & ref. & & AA & 146 & 45 & ref. & & AA & 97 & 20 & ref. & \\
\hline \multirow[t]{3}{*}{13} & \multicolumn{5}{|c|}{ rs4870056 (152204170); MAF (A): 0.5} & \multicolumn{5}{|c|}{ rs4870056 (152204170); MAF (A): 0.5} & \multicolumn{5}{|c|}{ rs4870056 (152204170); MAF (A): 0.5} \\
\hline & $\mathrm{AA} / \mathrm{AG}$ & 262 & 20 & $0.420(0.215-0.819)$ & 0.011 & $\mathrm{AA} / \mathrm{AG}$ & 401 & 130 & $1.136(0.807-1.599)$ & 0.464 & $\mathrm{AA} / \mathrm{AG}$ & 340 & 82 & $1.156(0.722-1.850)$ & 0.545 \\
\hline & GG & 104 & 18 & ref. & & GG & 157 & 46 & ref. & & GG & 124 & 25 & ref. & \\
\hline \multirow[t]{3}{*}{14} & \multicolumn{5}{|c|}{ rs2234693 (152205278); MAF (C): 0.5} & \multicolumn{5}{|c|}{ rs2234693 (152205278); MAF (C): 0.5} & \multicolumn{5}{|c|}{ rs2234693 (152205278); MAF (C): 0.5} \\
\hline & $\mathrm{CC} / \mathrm{CT}$ & 275 & 23 & $0.443(0.231-0.851)$ & 0.014 & $\mathrm{CC} / \mathrm{CT}$ & 413 & 129 & $1.037(0.740-1.452)$ & 0.834 & CC/CT & 381 & 88 & $1.275(0.761-2.135)$ & 0.356 \\
\hline & TT & 100 & 17 & ref. & & TT & 151 & 48 & ref. & & TT & 98 & 20 & ref. & \\
\hline \multirow[t]{3}{*}{15} & \multicolumn{5}{|c|}{ rs9340799 (152205324); MAF (G): 0.4} & \multicolumn{5}{|c|}{ rs9340799 (152205324); MAF (G): 0.3} & \multicolumn{5}{|c|}{ rs9340799 (152205324); MAF (G): 0.3} \\
\hline & GG/AG & 233 & 18 & $0.441(0.226-0.863)$ & 0.017 & GG/AG & 309 & 98 & $0.919(0.680-1.243)$ & 0.585 & GG/AG & 241 & 60 & $1.171(0.786-1.745)$ & 0.437 \\
\hline & AA & 143 & 21 & ref. & & AA & 254 & 79 & ref. & & AA & 239 & 48 & ref. & \\
\hline 16 & rs9322 & 332( & 5220 & 3744); MAF (A): 0.5 & & rs9322: & 332( & 5220 & 3744); MAF (A): 0.4 & & rs9322 & $332(1$ & 52208 & 3744); MAF (A): 0.4 & \\
\hline & $\mathrm{AA} / \mathrm{AC}$ & 257 & 21 & $0.483(0.248-0.943)$ & 0.033 & $\mathrm{AA} / \mathrm{AC}$ & 379 & 121 & $1.025(0.737-1.427)$ & 0.881 & $\mathrm{AA} / \mathrm{AC}$ & 146 & 77 & $1.399(0.891-2.196)$ & 0.145 \\
\hline & $\mathrm{CC}$ & 108 & 17 & ref. & & $\mathrm{CC}$ & 175 & 52 & ref. & & CC & 317 & 30 & ref. & \\
\hline 36 & rs2982 & 684( & 5234 & 3147); MAF (A): 0.1 & & rs2982 & $684(1$ & 52348 & 147); $\operatorname{MAF}(A): 0.1$ & & rs2982 & $684(1$ & 52348 & 3147); MAF (A): 0.2 & \\
\hline & $\mathrm{AA} / \mathrm{AC}$ & 61 & 6 & $1.120(0.461-2.725)$ & 0.802 & $\mathrm{AA} / \mathrm{AC}$ & 134 & 38 & $0.748(0.519-1.078)$ & 0.119 & $\mathrm{AA} / \mathrm{AC}$ & 159 & 41 & $1.745(1.152-2.644)$ & 0.009 \\
\hline & $\mathrm{CC}$ & 305 & 32 & ref. & & $\mathrm{CC}$ & 424 & 138 & ref. & & CC & 306 & 66 & ref. & \\
\hline
\end{tabular}

Adjusted for years of education, BMI, and presence of at least 1 APOE $\varepsilon 4$ allele. emp. p value = Empirical $\mathrm{p}$ value.

Black ( $\mathrm{n}=483,33.6 \%)$, while 380 women were self-identified as White $(26.4 \%)$. Among all participants, 329 were classified as having incident AD (22.9\%) and 1,107 as nondemented. The frequency of incident AD was greater in self-identified Blacks and Hispanics than in Whites (Blacks: 22.4\%, Hispanics: 31.6\%, and Whites: 10.5\%). BMI, history of diabetes mellitus, and current smoking status did not differ significantly between individuals with or without $\mathrm{AD}$ when all ethnicities were analyzed as a whole; however, there was a significant level of variability (table 3) among all covariates (BMI, presence of an APOE $\varepsilon 4$ allele, and years of education) between the three self-identified ethnicities.

\section{Analysis of ESR1 SNPs by Self-Defined Ethnicity}

Table 4 presents the locations and MAFs of ESR1 SNPs that were found to be associated with age at onset of AD by self-defined ethnicity. It also reports the association between these 
Janicki et al.: Estrogen Receptor $\alpha$ Variants Affect Age at Onset of Alzheimer's Disease in a Multiethnic Female Cohort

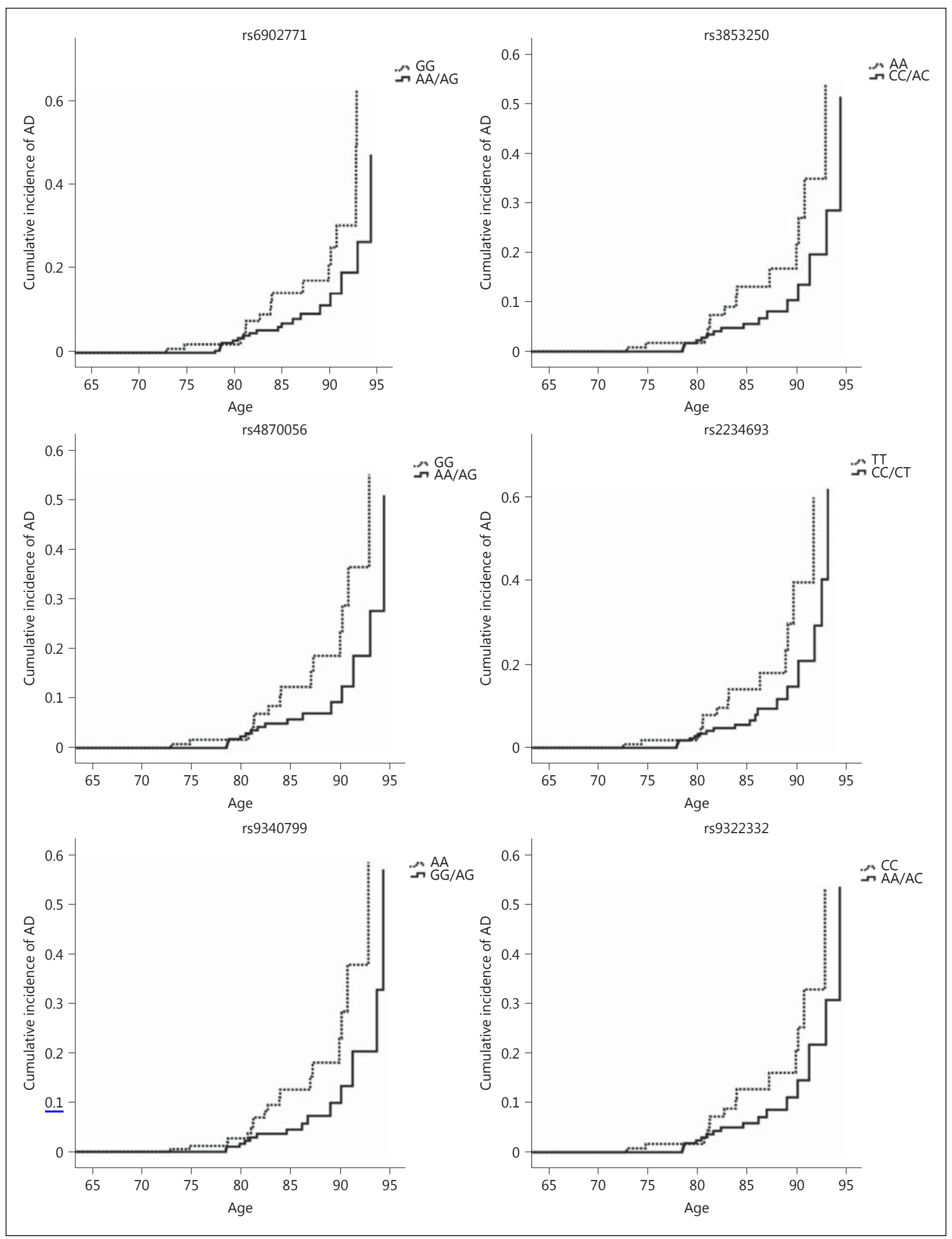

Fig. 2. Survival curves of ESR1 SNPs associated with incident AD in self-identified Whites. 


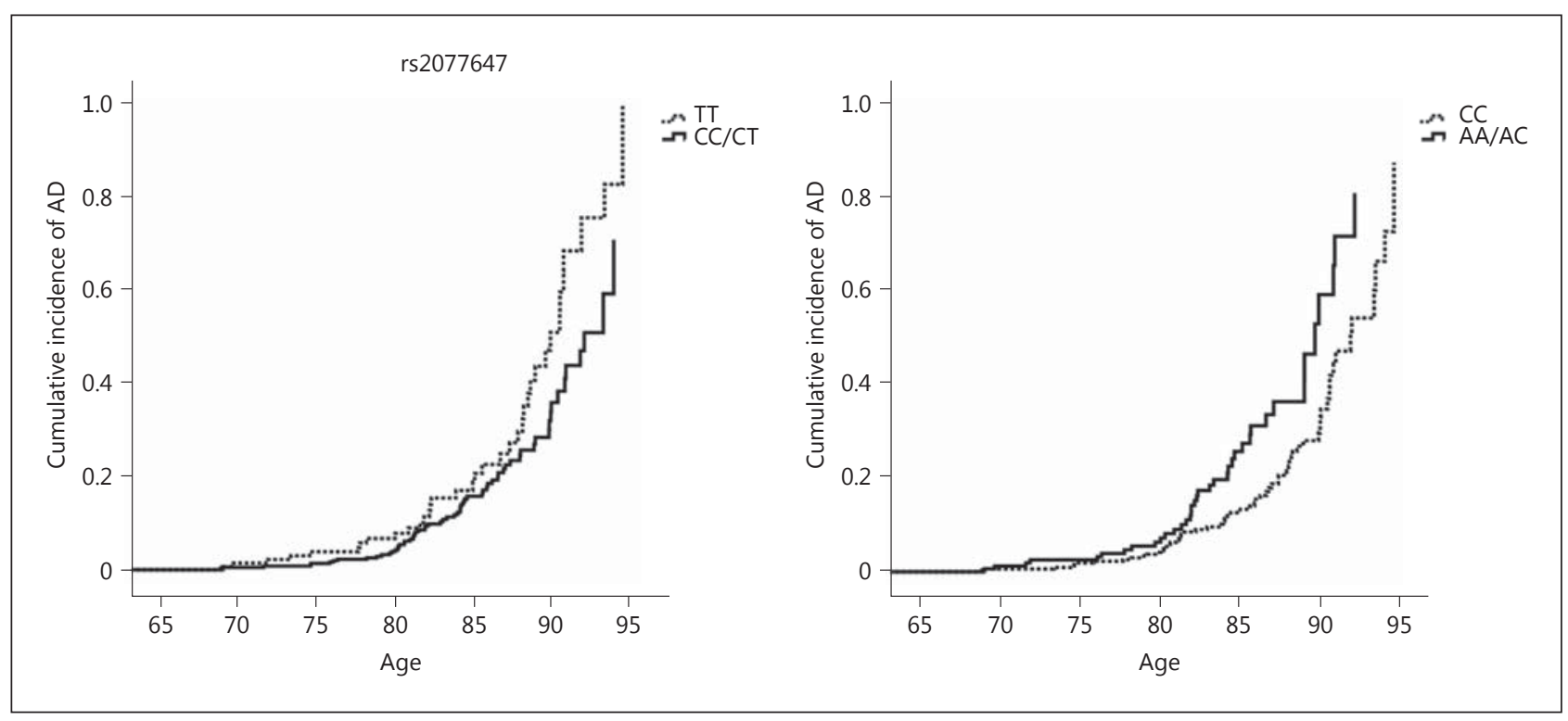

Fig. 3. Survival curves of ESR1 SNPs associated with incident AD in self-identified Blacks.

ESR1 genotypes and their hazard ratios (HR) for AD, stratified by self-reported ethnicity. After adjusting for BMI, years of education, and the presence of an APOE $\varepsilon 4$ allele, women who identified themselves as White and who were heterozygous or homozygous (i.e. carried one or two copies) for the A allele at rs6902771, for the C allele at rs3853250, for the A allele at rs4870056, for the C allele at rs2234693 (also known as the PvuII restriction site), for the G allele at rs9340799 (also known as the XbaI restriction site), and the A allele at rs9322332 had a roughly two-fold decrease in the $\mathrm{HR}$ for $\mathrm{AD}$ (table 4 ) (HR range $=0.420-0.483$ ) compared with women carrying no copies of these alleles (table 4) [HR for rs6902771 (AA/AG) $=0.437$, empirical $\mathrm{p}$ value $=0.015 ; \mathrm{HR}$ for rs3853250 $(\mathrm{CC} / \mathrm{AC})=0.442$, empirical $\mathrm{p}$ value $=0.017 ; \mathrm{HR}$ for rs4870056 $(\mathrm{AA} / \mathrm{AG})=0.420$, empirical $\mathrm{p}$ value $=0.011$; HR for rs2234693 $(\mathrm{CC} / \mathrm{CT})=$ 0.443 , empirical $\mathrm{p}$ value $=0.014$; $\mathrm{HR}$ for $\mathrm{rs} 9340799(\mathrm{GG} / \mathrm{AG})=0.441$, empirical $\mathrm{p}$ value $=$ 0.017 ; HR for rs9322332 $(\mathrm{AA} / \mathrm{AC})=0.483$, empirical $\mathrm{p}$ value $=0.033$ ]. Additionally, women who identified themselves as Black and who were heterozygous or homozygous (i.e. carried one or two copies) of the $C$ allele at rs2077647 and for the A allele at rs2982684 had an increase and decrease in the $\mathrm{HR}$ for $\mathrm{AD}$, respectively, compared with women carrying no copies of these alleles [HR for rs2077647 (CC/CT) $=0.629,95 \% \mathrm{CI}=0.414-0.955$, empirical $\mathrm{p}$ value $=0.0 .30 ; \mathrm{HR}$ for $\mathrm{rs} 2982684(\mathrm{AA} / \mathrm{AC})=1.745,95 \% \mathrm{CI}=1.152-2.644$, empirical $\mathrm{p}$ value $=0.009$ ] (table 4). Survival curves for these SNPs in self-identified Whites and Blacks are shown in figures 2 and 3. These SNPs were not significantly associated with increased or decreased HR for AD among women identifying themselves as Hispanic (table 4).

\section{Haplotype Analysis}

Pairwise LD was conducted between the six significant ESR1 SNPs in self-identified Whites, as implemented in the Haploview program using the $\mathrm{D}^{\prime}$ value [32] (online suppl. table 1). The possibility of multilocus association at adjacent variants was supported by the strong pairwise LD between SNP loci in this block, as well as the strong hazard rate findings at adjacent SNPs in this block (online suppl. fig. 1, see also table 4). In contrast, the 2 SNPs associated with increased or decreased likelihood of AD among African-Americans were not in strong LD (online suppl. fig. 3), indicating that they do not likely act by interaction with one 
Table 5. ESR1 SNPs associated with incident AD, by AIM-defined predominant genetic ancestry

\begin{tabular}{|c|c|c|c|c|c|c|c|c|c|c|c|c|c|c|c|}
\hline \multirow{2}{*}{$\begin{array}{l}\text { No. } \\
\text { of } \\
\text { SNP }\end{array}$} & \multicolumn{5}{|c|}{ Predominantly Caucasian AIM-defined ancestry } & \multicolumn{5}{|c|}{ Admixed AIM-defined ancestry } & \multicolumn{5}{|c|}{ Predominantly African AIM-defined ancestry } \\
\hline & SNP & $\mathrm{n}$ & $\mathrm{AD}$ & $\mathrm{HR}(95 \% \mathrm{CI})$ & $\begin{array}{l}\text { emp. } \\
\text { p value }\end{array}$ & SNP & $\mathrm{n}$ & $\mathrm{AD}$ & HR $(95 \%$ CI) & $\begin{array}{l}\text { emp. } \\
\text { p value }\end{array}$ & SNP & $\mathrm{n}$ & $\mathrm{AD}$ & $\mathrm{HR}(95 \% \mathrm{Cl})$ & $\begin{array}{l}\text { emp. } \\
\text { p value }\end{array}$ \\
\hline \multirow[t]{3}{*}{7} & \multicolumn{5}{|c|}{ rs6909023 (152195640); MAF (A): 0.1} & \multicolumn{5}{|c|}{ rs6909023 (152195640); MAF (A): 0.1} & \multicolumn{5}{|c|}{ rs6909023 (152195640); MAF (A): 0.2} \\
\hline & AA/AG & 48 & 4 & $1.862(1.030-3.366)$ & 0.040 & AA/AG & 166 & 36 & $0.264(0.470-1.230)$ & 0.264 & AA/AG & 103 & 37 & $1.135(0.760-1.696)$ & 0.536 \\
\hline & GG & 318 & 34 & ref. & & GG & 300 & 71 & ref. & & GG & 453 & 137 & ref. & \\
\hline \multirow[t]{3}{*}{36} & \multicolumn{5}{|c|}{ rs2982684 (152348147); MAF (A): 0.1} & \multicolumn{5}{|c|}{ rs2982684 (152348147); MAF (A): 0.2} & \multicolumn{5}{|c|}{ rs2982684 (152348147); MAF (A): 0.2} \\
\hline & $\mathrm{AA} / \mathrm{AC}$ & 159 & 17 & $0.720(0.383-1.354)$ & 0.308 & $\mathrm{AA} / \mathrm{AC}$ & 159 & 41 & $0.772(0.491-1.211)$ & 0.260 & $\mathrm{AA} / \mathrm{AC}$ & 134 & 38 & $1.528(1.040-2.244)$ & 0.031 \\
\hline & $\mathrm{CC}$ & 206 & 21 & ref. & & $\mathrm{CC}$ & 306 & 66 & ref. & & CC & 424 & 138 & ref. & \\
\hline
\end{tabular}

Adjusted for years of education, BMI, and presence of at least 1 APOE $\varepsilon 4$ allele. emp. p value = Empirical p value.

another but perhaps in relation to separate, unrelated markers. We performed a 'sliding window' haplotype analysis in the significant region in self-identified Whites, each analysis including 2-4 consecutive SNPs. While numerous haplotypes constructed from these ESR1 SNPs were found to be significantly associated with decreased risk for dementia (online suppl. table 1), the most robust associations in self-identified Whites were haplotype C-A-C-G at SNPs 12-15 (rs3853250 through rs9340799, OR 0.656, $\mathrm{p}=0.009$ ), which also contains the significant haplotypes A-C-G at SNPs 13-15 (rs4870056 through rs9340799, OR 0.656, p = 0.009 ) and C-G at SNPs 14-15 (rs2234693 through rs9340799, OR 0.658, p = 0.009).

\section{Analysis of ESR1 SNPs by AIM-Defined Ancestry}

We then repeated the analyses within strata specified by AIM-defined predominant genetic ancestry. Using this categorization, 1 unique SNP was found to be associated with increased HR (decreased age of onset of AD) among women of predominantly Caucasian genetic ancestry (rs9322332, $\mathrm{HR} \mathrm{AA} / \mathrm{AG}=1.862,95 \% \mathrm{CI}=1.030-3.366$, empirical $\mathrm{p}$ value $=$ 0.040) (table 5). Additionally, rs2982684, which had previously been found to be associated with decreased age at onset among self-identified Blacks, was also found to be associated with decreased age at onset among women of predominantly African genetic ancestry (rs2982684, HR AA/AC $=1.528$, empirical $p$ value $=0.31$ ) (table 5). Following recategorization using AIMdefined genetic ancestry, the 6 SNPs which previously had been found to be associated with delayed age at onset of AD among self-defined Whites (rs6902771, rs3853250, rs4870056, rs2234693, rs9340799, and rs9322332) were not found to be significant among women of predominantly Caucasian AIM-defined ancestry (online suppl. table 2). Likewise, rs2077647, which had been found to be associated with delayed age at onset among self-defined Blacks, was not associated with age at onset among women of predominantly African AIM-defined ancestry (online suppl. table 2).

\section{Discussion}

Six SNPs in ESR1 were associated with a more than two-fold decreased risk for AD among self-identified White women. Self-identified Whites with at least 1 minor allele at rs6902771, rs3853250, rs4870056, rs2234693, rs9340799, or rs9322332 had less than a one-half HR of AD compared with women without these risk alleles, indicating that these SNPs were associated with a delayed age of AD onset. These 6 intronic SNPs cover an 8.9-kb region with high LD (minimum pairwise $\mathrm{D}^{\prime}>0.8$ ), with rs2234693 (also known as restriction fragment length polymorphism, RFLP, PvuII) and rs9340799 (RFLP XbaI) located with $46 \mathrm{bp}$ of one another. Haplotype analysis revealed that 2-4 SNP combinations of risk alleles among these 6 SNPs 
were all significantly associated with decreased risk for $\mathrm{AD}$, with the most significant haplotype (C-A-C-G) including rs3853250, rs4870056, rs2234693, and rs9340799. When women were recategorized according to predominant AIM-defined genetic ancestry, these 6 SNPs were not associated with age at AD onset among women of predominantly Caucasian AIM-defined ancestry. However, only 1 SNP, rs6909023, was associated with an increased HR of AD (decreased age at onset) (table 5). The discrepancy between SNPs found to be significant by self-defined ethnicity versus AIM-defined predominant genetic ancestry confirms our hypothesis that the SNP effect on age at AD onset may be affected by environmental and/or cultural factors that affect women who define themselves as White, as opposed to women of predominant Caucasian genetic ancestry, as will be discussed in more detail below.

Among self-identified Blacks, women with at least 1 minor allele at rs2077647 had a significantly decreased HR (delayed age at onset) for AD; while women with at least 1 minor allele at rs2982684 had a significantly increased HR (earlier age at onset) for AD. When women were recategorized according to predominant AIM-defined genetic ancestry, rs2982684 continued to be associated with decreased age at onset of AD among women of predominantly African AIM-defined ancestry (table 5), while rs2077647 was no longer significant. The persistent association of rs2982684 with decreased AD age at onset despite ethnic group recategorization indicates that this SNP may have a more direct genetic effect on AD among women of self-identified Black ethnicity or predominantly African genetic ancestry.

Among women of Hispanic self-defined ethnicity and women of admixed AIM-defined genetic ancestry, no significant findings were demonstrated. This may be due to the fact that women in these groups demonstrate significant heterogeneity in predominant genetic ancestry as well as environmental risk factors, including diabetes mellitus, smoking, and education.

Differential association of polymorphisms in a susceptibility gene for AD in groups of different self-identified ethnicities may occur for several reasons. First, differences in LD patterns between ethnic groups may contribute to discrepancies in genotype associations (online suppl. fig. 1-3). In our group, SNPs, which were protective against AD in self-defined White women, were located within a defined LD block (online suppl. fig. 1, block 2). Notably, this block was less cohesive in self-defined Hispanics (online suppl. fig. 2, blocks 2-3) and self-defined Blacks (online suppl. fig. 3, blocks 3-4). This suggests that different LD patterns between ESR1 alleles and alleles of yet unidentified loci for susceptibility to AD between populations of different genetic ancestries may contribute to the observed variability in genotypic association. Second, it is also possible that differences in environmental or biological risk factors among women of different self-defined or genetic ancestries may play a significant role in phenotypic expression of the variants. This may explain why the 6 SNPs which were found to be protective in self-defined Whites were not found to be associated with age at $\mathrm{AD}$ onset among women of predominantly Caucasian genetic ancestry. As seen in online supplementary table 3, when ethnic group stratification was changed from self-defined ethnicity to predominantly AIM-defined genetic ancestry, the recategorization had the greatest effect on sample group when comparing self-identified Whites versus individuals of predominantly Caucasian AIM-based ancestry, and self-identified Black versus women of predominantly African AIM-based ancestry. Specifically, the shift in classification of race revealed that many individuals who identified themselves as Hispanic actually had genetic markers that were predominantly Caucasian or African. These individuals also had significantly higher rates of diabetes mellitus and smoking, and fewer years of education (online suppl. table 3) than individuals of predominantly African AIM who identified themselves as Black or participants of predominantly Caucasian AIM who identified themselves as White. The potential mediation of the SNP effect by vascular risk factors is reinforced by the different results in $\mathrm{p}$ values for Cox analyses performed with and without the inclusion of vascular covariates (online suppl. fig. 4). For example, the inclusion of several vascular risk factors in 
Janicki et al.: Estrogen Receptor $\alpha$ Variants Affect Age at Onset of Alzheimer's Disease in a Multiethnic Female Cohort

the Cox analyses (including history of diabetes and current smoking) attenuated the significance of SNPs in self-identified White women (online suppl. fig. 4). These discrepancies indicate that environmental and biological covariate risk factors may affect the association of different alleles with age at onset of $\mathrm{AD}$ in this group.

While it is possible that discrepancies in SNPs found to be significantly associated with age at onset of AD may be due to different MAFs between ethnicities, this was not the case in our study group. Comparisons of SNPs found to be associated with age at AD onset demonstrate no significant difference in MAF between self-identified ethnicities (tables 1,4) or between AIM-defined predominant genetic ancestries (table 5).

The association of polymorphisms in ESR1 with risk for AD has been investigated in a number of cohorts of Asian and European men and women, but findings have been inconsistent [10-18, 20-23, 33]. ESR1 is more than $140 \mathrm{~kb}$ long and has 8 exons and 5 domains [34]. The strongest associations within ESR1 have been found for the two RFLPs PvuII (-397 T/C; rs2234693) and XbaI (-351 A/G; rs9340799), located 46 bp apart in the first intron, which have been associated with risk for developing cognitive impairment and AD [10, 16, 18, 23]. These RFLPs have traditionally been recorded in PvuII as PP versus pp (where ' $\mathrm{P}$ ' is associated with the ' $\mathrm{T}$ ' allele, and ' $\mathrm{p}$ ' is associated with the ' $\mathrm{C}$ ' allele) and in $\mathrm{XbaI}$ as $\mathrm{XX}$ versus $\mathrm{xx}$ (where ' $\mathrm{X}$ ' is associated with the ' $\mathrm{A}$ ' allele and ' $\mathrm{X}$ ' is associated with the ' $\mathrm{G}$ ' allele). Capital ' $\mathrm{P}$ ' and ' $\mathrm{X}$ ' indicate the absence of the restriction site for each endonuclease, while lower case letters ' $p$ ' and ' $x$ ' indicate the presence of the restriction site. In our study, the $\mathrm{C}$ allele of rs2234693 (or ' $p$ ') and the G allele of rs9340799 (or ' $x$ ') were found to be protective, or associated with delayed age at AD onset. Conversely, the TT genotype of PvuII and the AA genotype of $X b a \mathrm{I}$ were found to be associated with earlier age at AD onset.

Several studies have similarly found an association between the T allele of PvuII and the A allele of $X b a \mathrm{I}$ and an increased risk for AD. One study of elderly Japanese men and women (205 cases vs. 92 controls), found a marginal association between the ' $\mathrm{X}$ ' polymorphism (A allele) of $X b a \mathrm{I}$ and risk for $\mathrm{AD}(\mathrm{p}=0.036)$, but no significant association between the PvuII 'P' polymorphism ( $\mathrm{T}$ allele) and risk for $\mathrm{AD}(\mathrm{p}=0.99)$ [15]. A second study of elderly Japanese found that frequencies of the ' $\mathrm{P}$ ' polymorphism ( $\mathrm{T}$ allele) of PvuII and ' $\mathrm{X}$ ' polymorphism (A allele) of the XbaI RFLPs were significantly higher in the AD group than in the control group (49.4\% P allele in AD cases vs. 36.3\% p allele in controls, $\mathrm{p}<0.01 ; 29.1 \% \mathrm{X}$ allele in AD cases vs. $16.7 \% \mathrm{X}$ allele in controls, $\mathrm{p}<0.01$ ] [33]. This finding was replicated by the same research group in two other studies of elderly Japanese, which included both men and women $[11,18]$. A study of elderly Han Chinese men and women also found overrepresentation of ' $\mathrm{P}$ ' or ' $\mathrm{X}$ ' polymorphisms ( $\mathrm{T}$ and $\mathrm{A}$ alleles, respectively) among AD patients compared with healthy controls (' $\mathrm{P}$ ' allele: $\mathrm{p}=0.023, \mathrm{OR}=2.94,95 \% \mathrm{CI}=1.13-7.1$; ' $\mathrm{X}$ ' allele: $\mathrm{p}=0.046, \mathrm{OR}=2.28$, $95 \% \mathrm{CI}=1.003-5.17$ ) [14]. This trend was more distinct in elderly Han Chinese women than men ('P' allele: $\mathrm{p}=0.016, \mathrm{OR}=3.68,95 \% \mathrm{CI}=1.22-11.08$; ' $\mathrm{X}$ ' allele: $\mathrm{p}=0.029, \mathrm{OR}=29.5,95 \%$ $\mathrm{CI}=1.10-7.94$ ) [14]. A study of elderly Italian men and women found the ESR1 'PP' (TT) and 'XX' (AA) genotypes to be associated with an increased risk for AD only in men (OR $=3.6,95 \%$ $\mathrm{CI}=1.2-10.9$ ) [22]. The lowest $A P O E$ concentrations were observed in men carrying 'PP' (TT) or 'XX' (AA) genotypes ( $\mathrm{p}=0.006)$, and in men carrying 'PP' (TT) and/or 'XX' (AA) genotypes together with the APOE $\varepsilon 4$ allele ( $\mathrm{p}=0.003)$. In women with AD, ESR1 'PP' (TT) and 'XX' (AA) genotypes were also associated with lower MMSE values ( $p=0.0007)$ [22]. Finally, a separate study of elderly Italian men and women that combined the alleles of the PvuII and XbaI polymorphisms demonstrated that the 'PPXX' (TTAA) haplotype was significantly more frequent in patients with $\mathrm{AD}$ than in controls [10]. The risk for $\mathrm{AD}$ increased by seven-fold in individuals homozygous for the APOE $\varepsilon 4$ allele with the 'PPXX' (TTAA) ESR1 genotype [10].

Conversely, other studies have demonstrated an association between the ' $p$ ' polymorphism (C allele) of $P v u I I$ and ' $\mathrm{X}$ ' polymorphism (A allele) of XbaI and increased risk for AD [16, 
Dementia

Cognitive Disorders \begin{tabular}{l|l}
\hline \multicolumn{2}{l}{ Dement Geriatr Cogn Disord 2014;38:200-213 } \\
\hline DOI: $\underline{10.1159 / 000355559}$ & $\begin{array}{l}\text { C 2014 S. Karger AG, Basel } \\
\text { www.karger.com/dem }\end{array}$ \\
\hline $\begin{array}{l}\text { Janicki et al.: Estrogen Receptor } \alpha \text { Variants Affect Age at Onset of Alzheimer's Disease } \\
\text { in a Multiethnic Female Cohort }\end{array}$
\end{tabular}

$17,20,23]$ or cognitive impairment [23], all in primarily homogenous Caucasian populations in Finland [16], Italy [17, 20], and the United States [23]. Finally, other studies have found no association between XbaI [12, 21, 35] or PvuII [12, 21] genotypes and risk for AD. Conflicting results between our data and the data reported within previous studies may be due to several factors. First, study designs differ in sample size. Second, a difference in ethnicities between samples is a well-known confounding factor in genetic studies. It is also possible that the increased risk for $\mathrm{AD}$ of cognitive impairment with $\mathrm{ER} \alpha$ polymorphisms is due to LD with nearby genes that may in turn cause increased risk for developing AD. Finally, the age at onset of disease and clinical manifestations of disease may be modulated by environmental or cultural factors. It is possible that various risk factors lead to differential rates of progression.

A number of hypotheses for the functional significance of these polymorphisms have been reported in the literature. Given their location, 397 and 351 bp upstream from the start of exon 2, possible functional mechanisms include changed ESR1 expression via altered binding of transcription factors and influence on alternative splicing of the ESR1 gene. Both these mechanisms can be a result of either of these polymorphisms or through LD with a truly functional, but so far unknown, sequence variation elsewhere in the ESR1 gene. To support the former hypothesis, Maruyama et al. [12] showed that the intronic region of the ESR1 gene carrying the PvuII and $\mathrm{XbaI}$ polymorphisms demonstrates a weak enhancer activity. Such activity appears to be influenced by genotype, as the enhancer activity of the $G$ allele appeared to be higher than the A allele. Additionally, according to Herrington et al. [36], the T allele of the PvuII RFLP eliminates a functional binding site for the transcription factor B-myb. This implies that the presence of this allele may result in lower ESR1 transcription or may alter stability or structure of the ER $\alpha$ transcript and the subsequent ER $\alpha$ protein. This is supported by one study which demonstrated that the PvuII T allele was associated with decreased plasma estradiol $\left(E_{2}\right)$ levels in an allele dose-dependent manner in postmenopausal women [37], and findings in other studies showing that the PvuII polymorphism T allele is associated with conditions affected by lower levels of $E_{2}$, including increased risk for osteoporosis [38, 39] and myocardial infarction [40]. The fact that the XbaI polymorphism A allele is also associated with lower $\mathrm{E}_{2}$ levels may be due to LD with the PvuII SNP or another functional polymorphism, or to functional significance of the $\mathrm{XbaI}$ polymorphism itself.

Overall, our findings confirm the findings of previous studies of a strong association between ESR1 polymorphisms and age at onset of AD among women. We also extend these studies through denser genotyping rather than relying on imputation that can introduce false positives in multiethnic cohorts. From this effort, we identified additional SNPs that are associated with AD risk and characterized how these SNPs vary among individuals of different AIM-defined ancestries. This allowed us to perform haplotype analysis among the 6 most significant SNPs in self-identified White women, which identified haplotype C-A-C-G at SNPs 12-15 (rs3853250 through rs9340799), containing the RFLPs PvuII and XbaI, as significantly decreased risk for developing AD (OR 0.656, $\mathrm{p}=0.009$ ). Moreover, our study clearly illustrates the importance of controlling for population stratification as well as for environmental risk factors in association studies, as SNPs, which we found to be associated with AD, vary significantly between the models within one ethnic group and among ethnic groups.

We noted that most examined SNPs were intronic, and therefore may not be the critical location of the pathological variants, but may serve as markers for the critical region or may otherwise influence the expression of critical genetic markers. Further studies may characterize other genetic mechanisms that may contribute to AD, including methylation and copy number variations. Future studies with denser genotyping to achieve high resolution in all ethnic groups, along with gene expression studies, may further provide biological insights. Additional insight may also be gained through future studies conducting similar analyses in men. 


\section{Acknowledgment}

Dr. Janicki is funded by NIH grant 5-T32MH020004-1, the Charles and Ann Lee Saunders Brown Fellowship Fund, and the Louis V. Gerstner Jr. Scholars Foundation. Ms. Park is funded by NIH grants 5P01 HD035897, R01 MH084995, and R01 NS060113. Dr. Cheng is funded by NIH grants U24 AG026395, R01 AG028786, R01 NS060113, R01 MH084995, R01 AG036469, and P50 AG008702. Dr. Clark is funded by NIH grants R01 NS060113, R01 NS073872, 5P50 AG008702, 1RC2NS070276, 2P50NS038370-11, the NINDS Parkinson's Disease iPS Cell Line Research Consortium and P50 'Genetics of Down Syndrome', and receives research support from the Alzheimer's Association, the Parkinson's Disease Foundation, and the Michael J. Fox Foundation. Dr. Lee is funded by NIH grants R37 AG15473, U24 AG026395, 5P01 HD035897, R01 MH084995, P50 AG008702, U01 AG023749, R01 NS060113, R01 AG036469, and receives research support from the Alzheimer's Association. Dr. Schupf is funded by NIH grants 5R01AG014673-09, R01AG037212, U01 AG023749, R01 AG028786, P01 HD35897, P50 AG08702, R01 AG034189, 1 R21CA125461-01A2, 1 R01AG034189,1 R01AG0306040-01,5R01AG007370-17, and receives research support from the Alzheimer's Association.

\section{Disclosure Statement}

Dr. Schupf has been a consultant for Elan/Jannsen Pharmaceuticals. All other authors reported no biomedical financial interests or potential conflicts of interest.

\section{References}

- 1 Shughrue PJ, Lane MV, Merchenthaler I: Comparative distribution of estrogen receptor-alpha and -beta mRNA in the rat central nervous system. J Comp Neurol 1997;388:507-525.

- 2 McEwen BS: Invited review: estrogens effects on the brain: multiple sites and molecular mechanisms. J Appl Physiol 2001;91:2785-2801.

3 Goodman Y, Bruce AJ, Cheng B, Mattson MP: Estrogens attenuate and corticosterone exacerbates excitotoxicity, oxidative injury, and amyloid beta-peptide toxicity in hippocampal neurons. J Neurochem 1996;66: 1836-1844.

4 Toran-Allerand CD, Miranda RC, Bentham WD, Sohrabji F, Brown TJ, Hochberg RB, MacLusky NJ: Estrogen receptors colocalize with low-affinity nerve growth factor receptors in cholinergic neurons of the basal forebrain. Proc Natl Acad Sci USA 1992;89:4668-4672.

- 5 Luine VN: Estradiol increases choline acetyltransferase activity in specific basal forebrain nuclei and projection areas of female rats. Exp Neurol 1985;89:484-490.

- 6 Behl C, Widmann M, Trapp T, Holsboer F: 17-beta estradiol protects neurons from oxidative stress-induced cell death in vitro. Biochem Biophys Res Commun 1995;216:473-482.

7 Jaffe AB, Toran-Allerand CD, Greengard P, Gandy SE: Estrogen regulates metabolism of Alzheimer amyloid beta precursor protein. J Biol Chem 1994;269:13065-13068.

8 Gerhard M, Ganz P: How do we explain the clinical benefits of estrogen? From bedside to bench. Circulation 1995; 92:5-8.

9 Simoncini T, Mannella P, Genazzani AR: Rapid estrogen actions in the cardiovascular system. Ann NY Acad Sci 2006;1089:424-430.

10 Brandi ML, Becherini L, Gennari L, Racchi M, Bianchetti A, Nacmias B, Sorbi S, Mecocci P, Senin U, Govoni S: Association of the estrogen receptor alpha gene polymorphisms with sporadic Alzheimer's disease. Biochem Biophys Res Commun 1999;265:335-338.

-11 Ji Y, Urakami K, Wada-Isoe K, Adachi Y, Nakashima K: Estrogen receptor gene polymorphisms in patients with Alzheimer's disease, vascular dementia and alcohol-associated dementia. Dement Geriatr Cogn Disord 2000; 11:119-122.

-12 Maruyama H, Toji H, Harrington CR, Sasaki K, Izumi Y, Ohnuma T, Arai H, Yasuda M, Tanaka C, Emson PC, Nakamura S, Kawakami H: Lack of an association of estrogen receptor alpha gene polymorphisms and transcriptional activity with Alzheimer disease. Arch Neurol 2000;57:236-240.

13 Lambert JC, Harris JM, Mann D, Lemmon H, Coates J, Cumming A, St-Clair D, Lendon C: Are the estrogen receptors involved in Alzheimer's disease? Neurosci Lett 2001;306:193-197.

14 Lin GF, Ma QW, Zhang DS, Zha YL, Lou KJ, Shen JH: Polymorphism of alpha-estrogen receptor and aryl hydrocarbon receptor genes in dementia patients in Shanghai suburb. Acta Pharmacol Sin 2003;24:651-656.

15 Usui C, Shibata N, Ohnuma T, Higashi S, Ohkubo T, Ueki A, Nagao M, Arai H: No genetic association between the myeloperoxidase gene -463 polymorphism and estrogen receptor-alpha gene polymorphisms and Japanese sporadic Alzheimer's disease. Dement Geriatr Cogn Disord 2006;21:296-299. 
Janicki et al.: Estrogen Receptor $\alpha$ Variants Affect Age at Onset of Alzheimer's Disease in a Multiethnic Female Cohort

16 Mattila KM, Axelman K, Rinne JO, Blomberg M, Lehtimaki T, Laippala P, Roytta M, Viitanen M, Wahlund L, Winblad B, Lannfelt L: Interaction between estrogen receptor 1 and the epsilon 4 allele of apolipoprotein $\mathrm{E}$ increases the risk of familial Alzheimer's disease in women. Neurosci Lett 2000;282:45-48.

$\checkmark 17$ Porrello E, Monti MC, Sinforiani E, Cairati M, Guaita A, Montomoli C, Govoni S, Racchi M: Estrogen receptor alpha and APOE epsilon 4 polymorphisms interact to increase risk for sporadic AD in Italian females. Eur J Neurol 2006;13:639-644.

18 Isoe-Wada K, Maeda M, Yong J, Adachi Y, Harada H, Urakami K, Nakashima K: Positive association between an estrogen receptor gene polymorphism and Parkinson's disease with dementia. Eur J Neurol 1999;6:431-435.

19 Isoe K, Urakami K, Adachi Y, Nakashima K: Genetic association of estrogen receptor gene polymorphisms with Alzheimer's disease. Alzheimer's Res 1997;3:195-197.

20 Monastero R, Cefalu AB, Camarda C, Noto D, Camarda LK, Caldarella R, Imbornone E, Averna MR, Camarda R: Association of estrogen receptor alpha gene with Alzheimer's disease: a case-control study. J Alzheimers Dis 2006;9:273-278.

21 Ma SL, Tang NL, Tam CW, Lui VW, Lau ES, Zhang YP, Chiu HF, Lam LC: Polymorphisms of the estrogen receptor alpha (ESR1) gene and the risk of Alzheimer's disease in a southern Chinese community. Int Psychogeriatr 2009;21:977-986.

-22 Corbo RM, Gambina G, Ruggeri M, Scacchi R: Association of estrogen receptor alpha (ESR1) PvuII and Xbal polymorphisms with sporadic Alzheimer's disease and their effect on apolipoprotein E concentrations. Dem Geriatr Cogn Disord 2006;22:67-72.

-23 Yaffe K, Lui LY, Grady D, Stone K, Morin P: Estrogen receptor 1 polymorphisms and risk of cognitive impairment in older women. Biol Psychiatry 2002;51:677-682.

-24 Tang MX, Cross P, Andrews H, Jacobs DM, Small S, Bell K, Merchant C, Lantigua R, Costa R, Stern Y, Mayeux R: Incidence of AD in African-Americans, Caribbean Hispanics, and Caucasians in northern Manhattan. Neurology 2001;56:49-56.

-25 Stern Y, Andrews H, Pittman J, Sano M, Tatemichi T, Lantigua R, Mayeux R: Diagnosis of dementia in a heterogeneous population. Development of a neuropsychological paradigm-based diagnosis of dementia and quantified correction for the effects of education. Arch Neurol 1992;49:453-460.

26 Pritchard JK, Stephens M, Donnelly P: Inference of population structure using multilocus genotype data. Genetics 2000;155:945-959.

27 Falush D, Stephens M, Pritchard JK: Inference of population structure using multilocus genotype data: linked loci and correlated allele frequencies. Genetics 2003;164:1567-1587.

-28 Farrer LA, Cupples LA, Haines JL, Hyman B, Kukull WA, Mayeux R, Myers RH, Pericak-Vance MA, Risch N, van Duijn CM: Effects of age, sex, and ethnicity on the association between apolipoprotein E genotype and Alzheimer disease. A meta-analysis. ApoE and Alzheimer DiseaseMeta Analysis Consortium. JAMA 1997;278:1349-1356.

29 Cauley JA, Gutai JP, Kuller LH, LeDonne D, Powell JG: The epidemiology of serum sex hormones in postmenopausal women. Am J Epidemiol 1989;129:1120-1131.

-30 Meldrum DR, Davidson BJ, Tataryn IV, Judd HL: Changes in circulating steroids with aging in postmenopausal women. Obstet Gynecol 1981;57:624-628.

-31 Judd HL, Shamonki IM, Frumar AM, Lagasse LD: Origin of serum estradiol in postmenopausal women. Obstet Gynecol 1982;59:680-686.

-32 Hixson JE, Vernier DT: Restriction isotyping of human apolipoprotein E by gene amplification and cleavage with HhaI. J Lipid Res 1990;31:545-548.

-33 Isoe K, Urakami K, Wakutani Y, Yong J, Adachi Y, Nakashima K: Screening for mutation of the presenilin 2 gene in Alzheimer's disease. Dement Geriatri Cogn Disord 1997;8:60.

-34 Ponglikitmongkol M, Green S, Chambon P: Genomic organization of the human oestrogen receptor gene. EMBO J 1988;7:3385-3388.

-35 Prince JA, Feuk L, Sawyer SL, Gottfries J, Ricksten A, Nagga K, Bogdanovic N, Blennow K, Brookes AJ: Lack of replication of association findings in complex disease: an analysis of 15 polymorphisms in prior candidate genes for sporadic Alzheimer's disease. Eur J Hum Genet 2001;9:437-444.

-36 Herrington DM, Howard TD, Brosnihan KB, McDonnell DP, Li X, Hawkins GA, Reboussin DM, Xu J, Zheng SL, Meyers DA, Bleecker ER: Common estrogen receptor polymorphism augments effects of hormone replacement therapy on E-selectin but not C-reactive protein. Circulation 2002;105:1879-1882.

-37 Schuit SC, de Jong FH, Stolk L, Koek WN, van Meurs JB, Schoofs MW, Zillikens MC, Hofman A, van Leeuwen JP, Pols HA, Uitterlinden AG: Estrogen receptor alpha gene polymorphisms are associated with estradiol levels in postmenopausal women. Eur J Endocrinol 2005;153:327-334.

38 van Meurs JB, Schuit SC, Weel AE, van der Klift M, Bergink AP, Arp PP, Colin EM, Fang Y, Hofman A, van Duijn $\mathrm{CM}$, van Leeuwen JP, Pols HA, Uitterlinden AG: Association of $5^{\prime}$ estrogen receptor alpha gene polymorphisms with bone mineral density, vertebral bone area and fracture risk. Hum Mol Genet 2003;12:1745-1754.

39 Ioannidis JP, Ralston SH, Bennett ST, Brandi ML, Grinberg D, Karassa FB, Langdahl B, van Meurs JB, Mosekilde L, Scollen S, Albagha OM, Bustamante M, Carey AH, Dunning AM, Enjuanes A, van Leeuwen JP, Mavilia C, Masi L, McGuigan FE, Nogues X, Pols HA, Reid DM, Schuit SC, Sherlock RE, Uitterlinden AG: Differential genetic effects of ESR1 gene polymorphisms on osteoporosis outcomes. JAMA 2004;292:2105-2114.

-40 Schuit SC, Oei HH, Witteman JC, Geurts van Kessel CH, van Meurs JB, Nijhuis RL, van Leeuwen JP, de Jong FH, Zillikens MC, Hofman A, Pols HA, Uitterlinden AG: Estrogen receptor alpha gene polymorphisms and risk of myocardial infarction. JAMA 2004;291:2969-2977. 